\title{
Connect-to-Connected Worlds
}

\author{
Piloting a Mobile, Data-Driven Reflection Tool for an Open-Ended Simulation at a
}

Museum

$\begin{array}{ccc}\text { Aditi } & \text { Leilah Lyons } & \text { Stephen Uzzo } \\ \text { Mallavarapu } & \text { NYSCI } & \text { NYSCI } \\ \text { UIC } & \text { Corona, NY } & \text { Corona, NY } \\ \text { Chicago, IL } & \text { llyons@nysci.org } & \text { suzzo@nysci.org } \\ \text { amalla5@uic.edu } & & \end{array}$

Wren
Thompson
NYSCI
Corona, NY

wthompson@nysci. org NY, NY

rlevycohen@fordham.edu

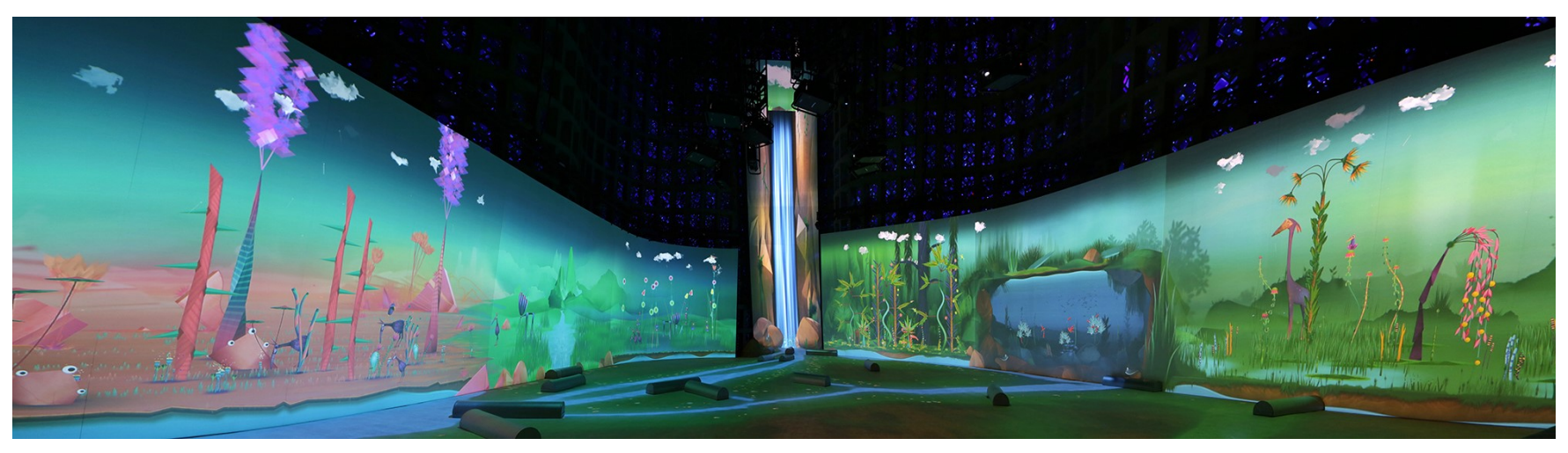

Figure 1: Connected Worlds exhibit showing the biomes and water sources (clockwise) - Desert, Mountain Valley, Plains, Waterfall, Jungle, Reservoir, Wetlands. The tangible logs are being used to direct water towards the biomes.

\begin{abstract}
Immersive open-ended museum exhibits promote ludic engagement and can be a powerful draw for visitors, but these qualities may also make learning more challenging. We describe our efforts to help visitors engage more deeply with an interactive exhibit's content by giving them access to visualizations of data skimmed from their use of the exhibit. We report on the motivations and challenges in designing this reflective tool, which positions visitors as a "human in the loop" to understand and manage their engagement with the exhibit. We used an iterative design process and qualitative
\end{abstract}

Permission to make digital or hard copies of all or part of this work for personal or classroom use is granted without fee provided that copies are not made or distributed for profit or commercial advantage and that copies bear this notice and the full citation on the first page. Copyrights for components of this work owned by others than the author(s) must be honored. Abstracting with credit is permitted. To copy otherwise, or republish, to post on servers or to redistribute to lists, requires prior specific permission and/or a fee. Request permissions from permissions@acm.org. CHI 2019, May 4-9, 2019, Glasgow, Scotland Uk

() 2019 Copyright held by the owner/author(s). Publication rights licensed to ACM.

ACM ISBN 978-1-4503-5970-2/19/05 ..\$15.00

https://doi.org/10.1145/3290605.3300237 methods to explore how and if visitors could (1) access and (2) comprehend the data visualizations, (3) reflect on their prior engagement with the exhibit, (4) plan their future engagement with the exhibit, and (5) act on their plans. We further discuss the essential design challenges and the opportunities made possible for visitors through data-driven reflection tools.

\section{CCS CONCEPTS}

- Human-centered computing $\rightarrow$ Interface design prototyping; Empirical studies in ubiquitous and mobile computing.

\section{KEYWORDS}

Reflective informatics, informal data literacy, museum exhibit design, systems thinking, CSCL

\section{ACM Reference Format:}

Aditi Mallavarapu, Leilah Lyons, Stephen Uzzo, Wren Thompson, Rinat Levy-Cohen, and Brian Slattery. 2019. Connect-to-Connected Worlds: Piloting a Mobile, Data-Driven Reflection Tool for an OpenEnded Simulation at a Museum. In CHI Conference on Human Factors in Computing Systems Proceedings (CHI 2019), May 4-9, 
2019, Glasgow, Scotland Uk. ACM, New York, NY, USA, 14 pages. https://doi.org/10.1145/3290605.3300237

\section{INTRODUCTION}

Informal learning environments like museums are constantly trying to strike a balance between enjoyment and learning to enhance the visitor experience [3]. Emphasizing enjoyment can result in "edutainment" or "Disney-fied" exhibits that can put the museum's mission to educate at risk, while a strict emphasis on learning can produce rigid, school-like exhibits that risk losing visitor engagement. Immersive digital technologies permit the creation of exhibits that employ inherently engaging forms of interaction like collaboration, whole-body movements, and the manipulation of tangible objects. But such exhibits run the risk of being victims of their own success, in that the interaction design can be so engaging in its own right that this ludic engagement can supplant or even interfere with visitors' ability to learn. Exhibit designers are constantly trying to find the "goldilocks zone" between supporting ludic engagement that piques the curiosity and exploration of visitors, and supporting the reflective engagement that helps visitors learn.

In this paper, we report on our explorations into how visitor reflection might be supported via the use of digital feedback on their use of an immersive exhiibt. The exhibit we used as a testbed is a large-scale, multi-user immersive ecology simulation exhibit installed in a science center in a major city in the United States. The exhibit has won multiple design awards, and visitors almost universally give it high marks on exit interviews, despite the fact that this exhibit's design violates virtually all of the known design principles for supporting learning with interactive exhibits [1]: (1) it has multiple interactive elements with equal salience, (2) it allows multiple users to interfere with one another, (3) it encourages visitors to disrupt the current state of the presented phenomena, and (4) it has features that make the critical phenomena hard to find when viewing the simulation. So it's not too surprising that visitors also often express confusion about "what was really going on" in the simulation. To be fair, the exhibit was intentionally designed to allow visitors to interfere with one another, as one of the learning goals is to convey how a lack of coordination among humans can affect natural systems (see Section 3), but even when visitors recognize the need to coordinate, they have a hard time knowing what to do. Changing the exhibit design at this point would be prohibitively expensive, so we had to look to other means for supporting visitors. Fortunately, we have access to logs of the simulation.

The challenge we gave ourselves was: how can we use logged exhibit use data to help visitors engage with the exhibit more reflectively? In this paper we report on several design iterations that saw us shifting our strategies in terms of form factors, data visualization design, and data visualization deployment. We uncovered several design directions that we suspect will be of interest to interaction designers who wish to support "learning in activity": per Greeno, the ways in which learning is both distributed across and situationally constrained by the activity system it occurs within [20].

\section{RELATED WORK}

Our work set out to investigate if data-driven feedback could promote reflection while learners are engaged with an exhibit. This section thus reviews what is known about designing for engagement, and prior work on providing learners with data-driven feedback on their actions.

\section{Designing for Engagement}

Museum exhibits, especially those in science centers, are typically intended to convey defined educational goals, even if those goals are meant to be learned via playful exploration [21]. This puts designers in a bit of a bind: for visitors to have the opportunity to learn, they need to be engaged [25], but interaction designs can be made so engaging as to actually interfere with learning the intended content [1].

Some designers have used the term "ludic engagement" [18, 37] to describe the way an interaction design can playfully encompass a user's attention. This is distinct from the state of engagement known as "flow", coined by Csikszentmihalyi, which requires that the "goals are clear, feedback is unambiguous, [and] challenges and skills are well-matched" [13]. In fact, ludic designs may deliberately promote ambiguity about what is happening and what the user can do [18, 37] to induce a feeling of enchantment [42]. Ambiguity and enchantment might be desirable outcomes for art museums [37], but for STEM museums, these feelings are not outcomes, but a precursor for learners to get more engaged with a new topic area [16].

One might argue, then, that interactive STEM exhibit designers should strive to first engage visitors ludically, with an alluring "hook" [21], but then transition visitors to more of a flow style of engagement, which has been proposed as a model for how to sustain interest so that learning can take place at an exhibit [13]. How to do this, though, is a complex question, involving how goals are defined (and by whom), how feedback is structured and supplied, how to attenuate challenges to accommodate visitors with different levels of skill, and how all of these elements interrelate. For example, structuring an exhibit to be open-ended (e.g., asking a visitor to build a creation of their own, rather than attain a fixed outcome) is one way to help visitors match skills-tochallenge, as visitors are free to define their own (hopefully attainable) goals [21]. But when visitors are setting their own goals, designing "unambiguous feedback" per [13] is more 
difficult. This is where digital log files can be useful - logbased feedback can be used to increase visitors' awareness of their actions, allowing them to judge their own progress towards their goals. Expert practitioners engaged in flow know how and when to seek feedback on their progress, but visitors may not. For example, when explanatory labels were added to inquiry exhibits, the counter-intuitive result was that visitor engagement with exhibits dropped [21]. By making feedback available too early via omnipresent labels, visitors "read ahead" and lost interest in further exploration, substituting a surface-level didactic explanation for engaged first-person learning. So exhibit designers need to decide how and when to deliver feedback, keeping in mind that feedback that is too complicated, or delivered too early or too late, can disrupt engagement.

\section{Designs for Supporting Reflection-with-Data}

Feedback is an integral part of reflecting on one's actions, which is in turn an integral part of learning [8]. By reflecting on one's actions, learners consolidate memories of experiences with their evolving mental model of the situation they are trying to understand. Here we review what is known about how to design data-driven feedback to support reflection on one's own actions.

Formats of Feedback for Reflection. In a study of data visualization comprehension which interviewed nearly 300 visitors at several science museums, it was found that visitors struggle with interpreting representations that go beyond simple forms like bar and line charts [7]. These findings echo the reflection-with-data choices being made in classrooms in the form of learning dashboards [6, 19, 34, 41, 49], which predominantly use simpler bar and line charts. But a review of the few reflection-with-data projects in museums show that richer data representations are in fact being used. One project visualized as a scatter-plot the calories burned by visitors using a whole-body interface to role-play as polar bears, as a way of illustrating the impact of climate change [26, 45]. Another project presented graphs of force and directional data to parents watching their child role-play as a meteor arcing around gravitational sources [48]. A third project used logs of choices made by visitors engaged with a tabletop circuit construction activity [29], which used a mix of feedback mechanisms: animated timelines for each user upon which their actions were superimposed, and dynamically-generated icon-and-text-based alerts [35].

The use of these richer representations (as compared to dashboards) may be a natural result of attempting to visualize feedback for embodied, immersive learning activities (rather than just quiz scores). In classrooms, the few examples of "quantified self" sensor-based learning experiences $[10,30,31]$ tend to use richer formats for reflection, like scatterplots [31], histograms [30], or even bespoke wearables that illustrate physiological data [10]. But these examples, as with the museum examples, the learning activities were designed to incorporate an adult (an explainer, parent, or teacher) to help make sense of the visualized data. Indeed, in another "quantified self" project that positioned students as the main users, simple bar graphs were used [17]. This suggests that the format of the feedback should be chosen in conjunction with the means of feedback delivery (e.g., whether or not it will be mediated by another person), as we will discuss next.

Means of Feedback Delivery for Reflection. The prior museum projects delivered feedback to someone other than the visitor expressly because of a concern that the visualizations would be too complicated for the visitor to decode while engaged [26, 29, 45, 48]. Not all of these means of delivery were equally effective. Positioning explainers as mediators of feedback makes sense in theory, as they presumably understand the exhibit content and are trained to help visitors make sense of exhibits, but in practice they sometimes struggled with incorporating the inherently dynamic data-driven feedback into their more didactically-inclined praxis [45]. They often missed opportunities to highlight the unique qualities of a particular visitor's data, defaulting to a more generic one-size-fits-all explanation. The most effective means of delivery seems to have been when the mediator (here, a parent) used the data to drive conversations taking the form of a recap or a story of what the child had just done within the exhibit [48]. This is in keeping with museum research (visitor-visitor conversation and the use of narratives are the most effective strategies for supporting general reflection [44]) as well as with the learning sciences [14]. But when these conversations should be had is the question we will explore next - should they be planned or capitalize on spontaneous "teachable moments" [23]?

Timing of Feedback Delivery for Reflection. In the prior museum projects using explainers as mediators, a major concern was when the explainer should intervene. Despite intentionally designing the system to spur the delivery of "just-in-time" intercessions, like the "explanatoids" that have been shown to be an effective means of scaffolding in museum learning conversations [12], the mediators found it awkward to intercede while the visitor was engaged [26, 45]. In prior work, the most productive reflection occurred in the form of recap discussions after the conclusion of an orbit attempt [48]. This suggests that the exhibit activity may need to be designed to have "breaks in the action" for visitors to receive feedback to reflect on what they have done. 


\section{DESIGN PROCESS}

The desire to create a mobile tool for visualizing visitor data did not spring fully-formed from our museum's research and design team, however. In this section, we describe the immersive exhibit in more depth, justifying the need for additional interpretive support for the experience, and stepping through an early experiment with providing visitors with data for reflection.

\section{Motivation: "Dis-Connected" Worlds}

The New York hall of Sciences opened a one-of-a-kind immersive multi-user exhibit called Connected Worlds in 2015. The exhibit is comprised of six $4 \mathrm{~m}$-high and one $12 \mathrm{~m}$-high projection screens, and a $214 \mathrm{~m}^{2}$ projection floorspace, seamlessly melded into a continuous simulation of an ecosystem (see Figure 1). This ecosystem consists of four biomes (the Desert, Grasslands, Jungle, and Wetlands) and three sources of water (Waterfall, Reservoir, and Mountain Valley).

Interaction Design. Visitors interact with the simulation by diverting the flow of water projected on the gallery floor, and by planting seeds in the biomes on the wall projections. They can plant seeds in by holding their hand up in front of the screens, and dropping their hand when the seed they want to plant appears on-screen. If sufficient water is present, the seed will sprout. Different plants attract and support different animals as sources of food or shelter. The simulation includes a simplified model of "ecological succession", meaning that initially visitors can only plant small plants like grasses, but when sufficient grasses are present, the "soil" can support larger, more elaborate plants. Visitors supply water to the biomes by dragging large stuffed "logs" around the floor of the exhibit, diverting the flow of water from the 6-story Waterfall and the Mountain Valley and Reservoir screens. When water is supplied to a biome it gets collected as "groundwater." The plants in the biomes cause water from the biomes to evaporate and form clouds, which return water to the ecosystem, emulating a real-world water cycle.

Twelve Kinect cameras detect the user gestures in front of the screens and three InfraRed (IR) cameras detect the placements of the "logs" (which are coated in an IR-reflective fabric) on the exhibit floor. Up to 50 visitors can simultaneously interact with the exhibit at one time. The interaction design is simple and enjoyable enough to allow visitors of a full range of ages (from toddler to adult) to engage with the simulation, but the learning goals were selected to be accessible to upper elementary and middle school students. The exhibit can be facilitated in a number of ways, from open-ended free-play sessions to more structured challenge sessions intended to be used with school groups.
Learning Goals. The exhibit was intended to introduce visitors to concepts from ecology (like diversity and sustainability), and to complex systems concepts (like feedback loops, tipping points, and telecoupling). Further, the exhibit was intentionally structured as a participatory simulation [11], meaning that each person's actions influence the unfolding state of the simulated ecosystem. To attain and sustain a healthy ecosystem, visitors need to figure out how to collaborate and resolve inevitable resource conflicts.

Learner Response. Connected Worlds has won multiple awards for innovation in design, and the response from visitors has been overwhelmingly positive, but there is ample evidence (from observing researchers and floor staff) that many visitors experience the exhibit primarily as an interactive play space and can struggle with understanding the intended learning goals, and with knowing how to work together to manage the ecosystem. In exit interviews, visitors often express sentiments like: "That was amazing! So much fun... but I couldn't understand what was going on. Things would be going great but then all my plants would just die sometimes," or, "They [referring to another group of players] kept stealing our water - we tried to tell them that we needed it but they didn't listen."

Almost universally, visitors equate a biome's "health" with the number of plants and animals present, ignoring whether the ecosystem was diverse or sustainable over time. It was clear that the visitors had a hard time understanding the systemic relationships present in the simulation (e.g., that plants constantly consume water, so while a player can plant a large number of seeds and see them successfully sprout, over time the plants will consume the water until the biome collapses - a tipping point). With respect to our collaborative learning goals for the exhibit, we embrace that visitor groups might have different motivations (e.g., some want to compete with one another, others wish to sow destruction, while other wish to engage in exploratory play). These kinds of experiences can be educationally valid and valuable, by revealing ecosystem and complex system principles and by showing the consequences of not collaborating. However, their experiences will not be very educational if visitors cannot understand what actions led to certain outcomes, and visitors should be able to collaborate when they wish. Via observations and post-visit interviews, we found that collaboratively-inclined visitor groups were often stymied by a lack of information when making water distribution decisions, relying on imperfect heuristics like turn-taking. Ironically, we discovered that visitors need help making connections in Connected Worlds. 


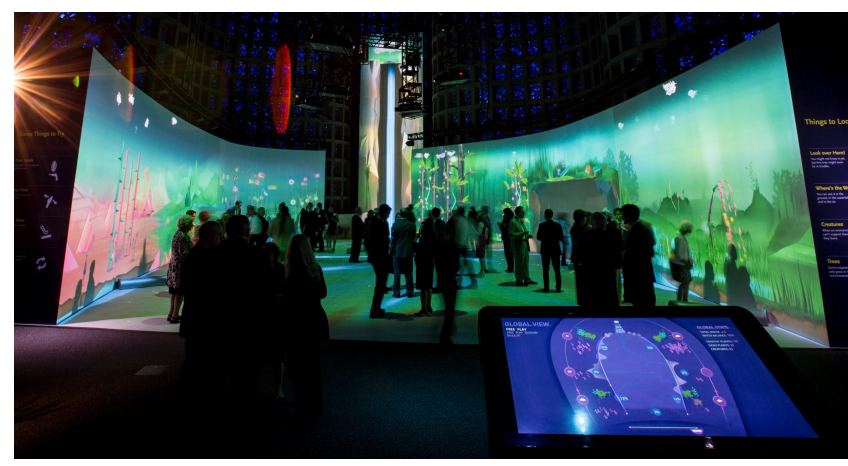

Figure 2: View of the Global View touchscreen, as installed in front of the entrance to the Connected Worlds exhibit.

\section{Global View: A "Reflection Station"}

Part of the original design for Connected Worlds was the Global View touchscreen, a "reflection station" which allows visitors to quite literally step back and gain an overview of what is happening (and has happened) within the simulation (see Figure 2). Developed with the advice of the Connected Worlds advisory board, and drawing heavily from research that showed that young learners prefer representations of data that resemble the items being represented [32], Global View represents the system state using icons superimposed on a top-down schematic view of the exhibit (see Figure 3).

Interface Design. The flow of water is illustrated in light blue streams on the floor, and the supply of groundwater at a given biome or water source is represented by the amount a blue circle is filled (see contrasting Desert and Wetlands water supplies in Figure 3). The number, types, and living/dead status of plants is illustrated by icons next to each biome. The migration of clouds (produced via plant transpiration) is shown in the outer pink arc. By default Global View shows the current state of the simulation, but a user can see how the ecosystem state evolved over time by dragging a slider.

Learner Response. While visually attractive, we found that there were two main problems with Global View. The first is a simple problem of access. Because the floor of Connected Worlds is an active interaction space, we couldn't place Global View inside Connected Worlds. It would have both interfered with the ability to detect the placement of the IR-reflective logs and been a collision/trip hazard for children. So in order to consult Global View, visitors would have to step away from their ludic engagement with Connected Worlds - and observations showed that this didn't happen. The second problem was one of comprehension: formative studies showed that visitors were easily able to link between the iconographic representations and the referents in the Connected Worlds exhibit space, but visitors struggled with

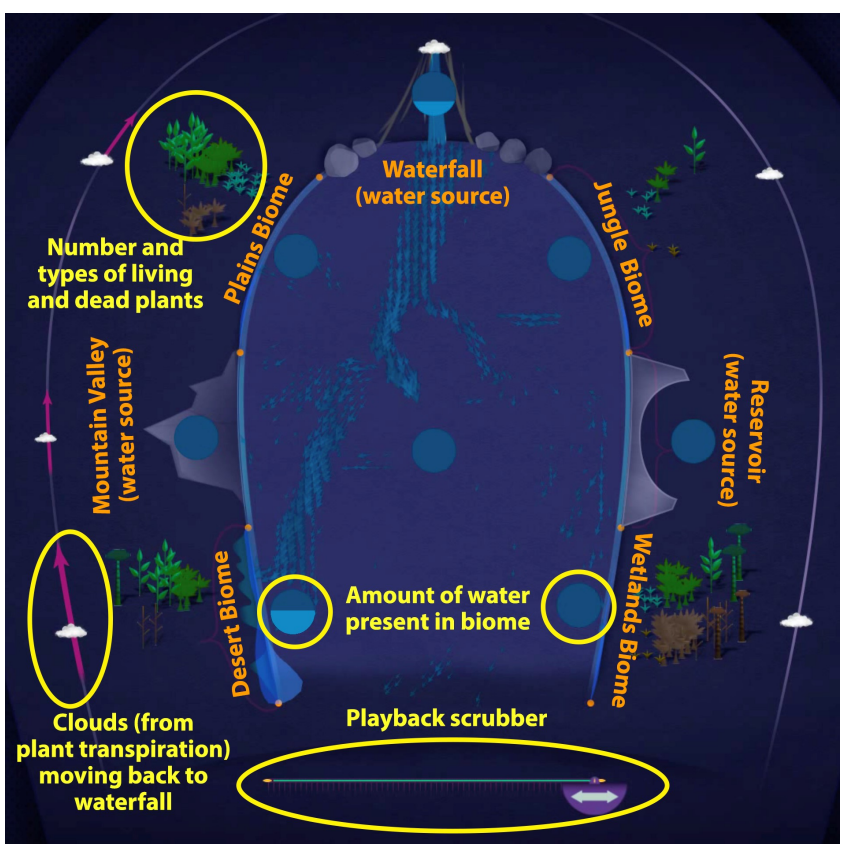

Figure 3: Detail of the Global View touchscreen, with yellow callouts describing the iconographic elements and orange text labeling regions of the simulation.

deriving useful information from the display. We intentionally designed Global View to be a general-purpose reflection tool, because open-ended prompts for reflection are better for reflection [14], and because Connected Worlds itself is a very open-ended learning experience. But much like the Connected Worlds exhibit itself, the Global View (in both live and playback mode) was lovely, engaging, and provided altogether too much detail for visitors to make sense of it.

\section{Designing Connect-to-Connected Worlds}

Based on our experiences with Global View we determined that we needed to fix the observed problems of access and comprehension. We were not in a position to alter the Connected Worlds exhibit itself, so making use of a mobile tablet platform seemed an obvious choice for supporting access - if you can't bring the visitors to the data, bring the data to the visitors. With respect to comprehension, we based our design decisions on the prior work done with providing learners with data for reflection on their own actions (see Section 2). The prior work suggested that we should (1) use very simple data representations, (2) use data representations that would help visitors form a narrative about their use of the exhibit, (3) enlist a non-engaged mediator as the main user of the data visualization, and (4) build into the Connected Worlds activity a period to "pause" and engage in reflective discussion with the visualization. It is important to note that the third and fourth design principles listed here do not speak 
to the design of the data visualization technology directly, but rather, to the way in which the use of the technology is situated in the social and structural contexts of the learning activity design. Using these general ideas, we set about constructing Connect-to-Connected Worlds (CtCW), a webbased dashboard which visualizes data extracted from the visitor interactions with Connected Worlds on tablet devices.

Technical Implementation. The Connected Worlds developers built in two methods of accessing data on the state of the simulation: (1) retrospectively, as a data dump at the end of a Connected Worlds session, stored in a CSV format, and (2) live, via a local web portal, where a stakeholder (e.g., a museum administrator or facilitator) could view the current state of simulation variables (but no history of the states of those variables). For this project, we decided that the live data would give us more flexibility in deployment, and thus wrote a script to scrape this live data and store it in a MySQL server. We capture a snapshot just about every second, although latencies can result in up to $5 \mathrm{~s}$ of delay in visualizing the data. (Note that neither the retrospective nor the live data run afoul of privacy concerns, as the data pertains only to the system state, and not the individual users' actions or identity). The data is visualized via a custom web interface (implemented in JavaScript Library D3) intended to be viewed on a tablet (we supplied 12.9" Apple iPads for this study).

Segmenting Sessions for Facilitated Reflection. A Connected Worlds session is designed to be run in segments, which gave us latitude to build a period of reflection into the sessions (indeed this was already how many explainers facilitated Connected Worlds, using the pause between segments to review the prior segment). As part of their mediation, we would ask the explainers to facilitate a group discussion that would put the visitors in the role of using the data to help tell the story of what happened during a prior segment, and to plan what they should do in the next segment, so that we could incorporate two strategies (visitor-visitor discussion and narratives) known to support visitor reflection [44].

Selecting Data to Maximally Inform Expected Actions. Given the known challenges visitors have with data representations [7], we opted to use the simplest and most popular data representation used in reflective learning dashboards: the bar chart [41]. To select the data to visualize, we wanted evaluate the potential for visualizations to promote reflection, planning, and action, so we revisited challenges that staff and research personnel had observed visitors facing. We tried to limit for our consideration only those variables that could nudge the visitor towards action. One of the most common obstacles to visitor action we saw was that although the level of groundwater available for plants in a biome was visualized in Connected Worlds (see the blue band at the bottom of the leftmost Desert biome in Figure 1), visitors had no way to relate this volume to the amount of water the plants in the biome needed to consume. They would often be surprised when, after overplanting a biome, the plant population would collapse. So for our pilot, we created a "Plants vs. Water Summary" column graph, by computing the average amount of available groundwater and juxtaposing it against the average amount of water needed by the plants present in each biome (see Figure 4). This would allow visitors to see if in the prior segment they had overplanted relative to the water supply (as was true for the Plains, Jungle, and Desert biomes in Figure 4), or whether they had planted "within their means" (as was true of the Wetlands biome in Figure 4).

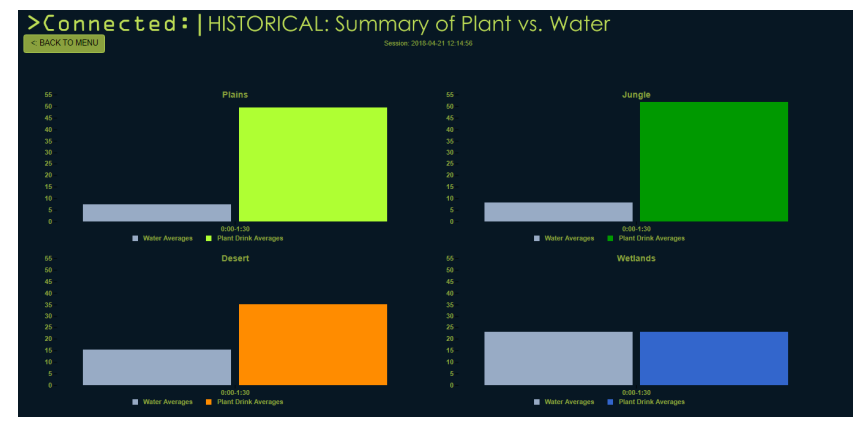

Figure 4: Screen-shot of the Plants vs. Water Summary visualization. The blue-grey bars illustrate the average amount of groundwater present, and the colored bars represent the average amount of water the plants needed, for the Plains (yellow), Jungle (green), Wetlands (blue) and Desert (orange) biomes.

Variations in Visualization Design for CtCW. During the process of exploring the design space for CtCW, we created a number of other candidate data visualizations. Several were based on different variables and as such would provide drastically different feedback, thus changing the goals visitors might choose for themselves in the activity, so we did not test them in this small pilot. Two visualizations provided information closely related enough to the Plants vs. Water Summary that we thought participants might be able to make sense of them in a post-activity focus group.

The Continuous Plant vs. Water Visualization shown in Figure 5 uses the same data as the Plant vs Water Summaries, but in a line graph representation. This representation is particularly compelling when shown live during a segment, as the lines are drawn dynamically in real time. It also provides nuance not present in the Summary view - for example, a Summary column graph of Figure 5 might show an abundance of water, missing that the plant needs began to outstrip the available supply just before the segment end. 


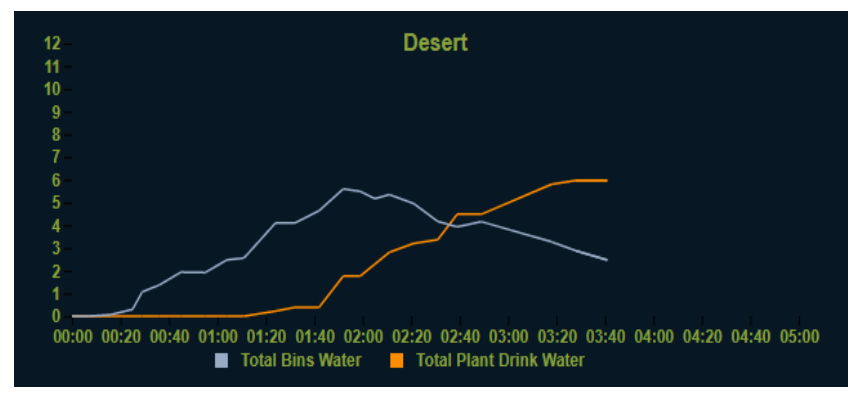

Figure 5: Screen-shot detail of a Plants vs. Water Summary graph, demonstrating how multiple session segments can be shown.

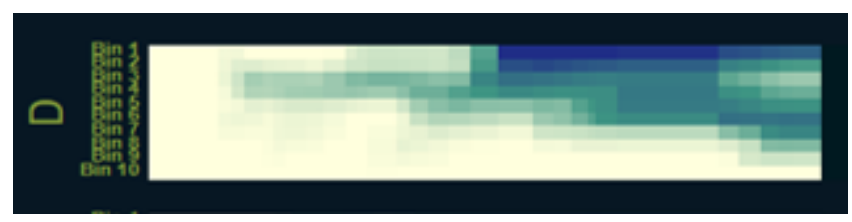

Figure 6: Screen-shot detail of the Water Bin visualization for the Desert. A snapshot of the water level in each water bin is visualized as a column, with time increasing on the $x$ axis, and the color changing from white to dark blue as the depth of water present increases.

The Water Bin Visualization shown in Figure 6 gives needed details on how water is distributed across a biome: groundwater is not one pool distributed evenly, it is actually divided into 10 "bins," so it matters where within the biome water gets directed. Plants vs. Water representations might show "plenty" of water present in a biome, when in actuality the water is present in bins that are not supporting any plants. Additionally, visitors often get confused when they try to plant a seed in a "dry" bin and it fails to thrive. In Figure 6, the Desert initially lacks water, but over time, a deep pool of groundwater forms in one corner of the biome screen.

\section{STUDY DESIGN}

As researchers situated within a museum we are subject to institutional interests \& constraints. Given the prior failure of Global View, we needed to gauge whether $\mathrm{CtCW}$ had any potential for success to gain internal support for future work. For our study, then, we defined "success" as whether and if participants could (1) access and (2) comprehend the data visualizations, and then use them to inform their (3) reflection, (4) plans, and (5) actions. Stake [47] notes that selecting multiple cases is often done to maximize what can be learned about a phenomenon. We were curious to see what was possible when we removed known obstacles for reflecting-with-data by intentionally selecting the participants (adults-only), scenario (facilitator-led reflection during a pause in activity),
\& visualization style (column graphs). By pairing this "bestcase" case with a case absent the visualization using a closed two-case design [50], we set up a contrast that could give us an "existence proof," to see the extent to which the genre of mobile data-driven reflection technology could impact targeted visitor behaviors, and to form a baseline against which we can contrast future, more challenging use cases (e.g., mixed-age groups; with explainers facilitating, or with parents facilitating). Observing the changes needed to adapt $\mathrm{CtCW}$ to new use cases will further illuminate design issues for this genre of technology. After the sessions concluded, we then engaged the visitors in a focus group discussion, where we could show them the variations in visualizations, and probe them about other ways they might want to use Connected Worlds data to reflect.

\section{Participants}

The pilot trial was conducted with 26 adults including 11 women and 15 men (aged 22-57 years, $M=33$ ) for one hour on a Saturday. The adults chosen for the study were a part of a volunteer group that were visiting the museum, with no prior Connected Worlds experience. All chose to consent according to our IRB procedures. We chose to work with this adult group partly out of convenience, as the logistical need to have $12+$ people present and consented in order to run just a single session has proven to be surprisingly difficult when also trying to control for visitor age (parents typically attend the museum with children of multiple ages, and do not like separating their children), working around existing bookings of the exhibit space, and complying with state Board of Education IRB requirements (we are not able to record students on school trips).

We reasoned that adults new to the exhibit would be best positioned to reveal if there was any potential value to visualizing Connected Worlds data for visitors: they would have the most need for help understanding the exhibit, they would have the best chance of understanding the data representations, and they would likely be able to be articulate about their plans. These volunteers were in keeping with the diverse ethnic demographics of our visitors (30\% white, $30 \%$ Hispanic/Latino, $40 \%$ Asian/Indian), and their education level (10\% High School, 65\% Bachelor's, 25\% Graduate) matched our visitor education demographics as well as general demographics for science centers [28]. If our study revealed if and how these adults could make use of data-driven feedback to reflect, plan, and act, we could then begin to explore how to adapt $\mathrm{CtCW}$ to work for more challenging scenarios (like school groups; or family groups where parents might directly use CtCW, a scenario our Visitor Services department wanted us to discuss in the post-activity focus groups). 


\section{Procedure}

We divided the participants into two sessions. One session (12 adults) saw the Summary of Plants vs Water visualization (see Figure 4) during the structured discussion while the other (14 adults) did not. In each, the adults were divided into 4 teams each assigned to a biome, each team wearing a differently-colored vest. The vests were clipped with digital lapel recorders that would record the visitors' conversations.

Sequencing. The groups played two 5-minute-long segments, with a 5-minute period in-between for a facilitated discussion, and followed by 10 minutes for a survey and a focus group discussion. The facilitator was a member of the research team, and followed a script for how to introduce the exhibit and facilitate the discussion section. During the discussion, the visitors were asked what their goals had been during the first segment, and (after either seeing the visualization, or not) were asked whether they would change them for the second segment. In the session where the visualization was shown (Feedback Session), the facilitator explained which biome each of the four graphs pertained to, that the blue-grey bars indicated the average amount of water supply during the segment, and that the other bars indicated the average amount of water the plants needed during the segment. No other explanation was given of the representation or how to use it, the intent being to allow participants to craft their own narratives about their prior use of the simulation, and their own goals and plans moving forward. The participants were asked to take a survey after the conclusion of the second segment which collected demographic information, and (for in the Feedback Session) their perceptions of the utility of the data visualization. Both groups then participated in a focus group discussion with the researchers, where we presented all three visualization types (Plants vs. Water Summary, Continuous Plants vs. Water, and Water Bins), using the visualizations as a jumping-off point to probe the visitors' preferences for feedback.

Analysis. The surveys and audio records were labeled with each participant ID to link participant responses and audio transcripts. The audio recordings for the discussion periods were transcribed and thematically analyzed by two coders independently performing "process coding" [36] for the targeted comprehending, reflecting, and planning processes. Any disagreements about code assignments and where codes started/stopped (i.e., unitization) were resolved through discussion. The comprehending code was applied to talk demonstrating that information was correctly derived from the visualizations. The reflecting code was applied to talk that demonstrated both recall and evaluation of prior actions, and, in the Feedback Session, talk that related information

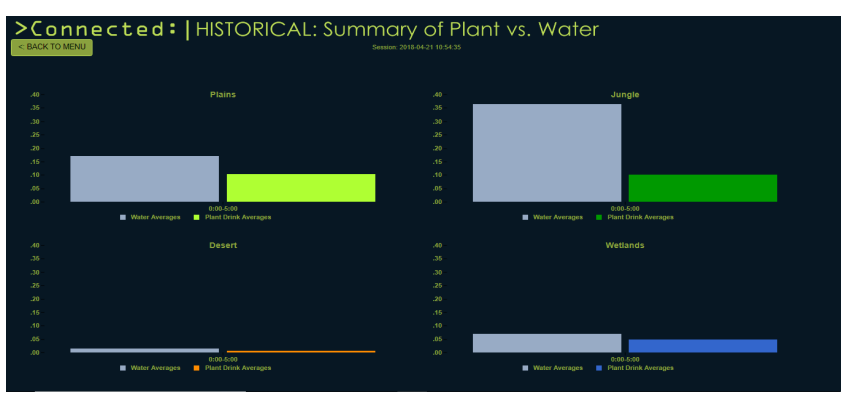

Figure 7: Screen-shot of the Plants vs. Water Summary shown during the Feedback Session's discussion period after the first segment of exhibit use.

derived from the visualizations to prior actions. The planning code was applied to talk making action proposals or responding to such proposals. We visualized collected log data to see if the plans proposed by visitors were translated into actions.

\section{STUDY RESULTS}

We wanted to know how and if the visitors could comprehend the data-driven feedback, and by comparing the cases, we hoped to be able to detect and characterize any differences between the Feedback and Non-Feedback groups in terms of participants' reflection, planning, and actions. From the focus groups, we wanted to investigate what kind of access visitors wanted to have to feedback derived from Connected Worlds data, and gather suggestions for how to deploy feedback for other scenarios of use (like parents using CtCW to mediate child learning).

\section{Visitors' comprehension of data representations}

The survey contained two 5-point Likert scale questions about the comprehensibility of the data representation ranging from 1 (strongly disagree) to 5 (strongly agree). While selfreports of comprehension are not necessarily reliable, they are critical for evaluating free-choice learning experiences, as visitors are known to avoid exhibit elements perceived as being too difficult. The 12 respondents in the Feedback Session responded positively to both of these. Nine participants gave a rating of 4 and three a rating of 5 to the question of whether the representation was helpful for "understanding what my group was doing at our biome" $(n=12, M=4.3)$. With respect to whether or not the representation was helpful for "understanding what all the groups were doing at their biomes," nearly identical ratings were given, although one respondent gave a 2 in lieu of a 4 rating $(n=12, M=4.1)$.

More persuasive evidence of visitor comprehension emerged from the coded talk taken from the Feedback Session's 
discussion phase. After the facilitator introduced the visualization (Figure 7), group members exhibited no evidence of challenges in comprehending the representation, quickly deriving information from the display. Some comprehending talk referred to the water supply levels alone, but most participants made the ratio comparison between water supply and plant requirements, as evidenced in conversation by repeated references to what biomes "needed," or to water being "wasted." (It is worth noting that these examples, along with the vast majority of comprehending talk, were also coded as reflecting talk, as in most instances a speaker introduced a piece of information drawn from the visualization in order to levy judgment on it).

Initially, participants seemed to focus on deciphering information pertaining just to their own biome. For example, a Plains team member detected a high water supply bar for their biome, remarking "We didn't need that water" [P2-1], despite the fact that the Jungle had even more, while a Wetlands team member remarked "Wow, the wetlands barely got any" [W2-4], referring to the low water supply bar for the Wetlands, seemingly oblivious to the fact that the Desert had even less (See Figure 7).

As the discussion progressed, participants began using the visualization to derive information about other biomes, and then to compare them, as when a Desert team member remarked that "so neither of these two needed water, neither of these two" [D2-1] in reference to the Plains and Jungle. Some participants used the visualization to derive information about what had happened across the system as a whole, as when another Desert team member exclaimed that, "we didn't need that much water, that's not good...we wouldn't need that much water that we wasted." [D2-2], referring to the fact that across all biomes, the grey water supply bars were higher than the plant water need bars.

The coded talk demonstrated that in group discussion the participants were clearly able to extract and comprehend a number of forms of information from the display: interpreting the ratios of water supply and plant needs for a single biome, comparing individual variables (water supply levels) across biomes, and detecting multi-variate patterns (the ratio of water supply and plant need levels) across biomes.

\section{Visitors' reflection on prior actions}

We coded talk as reflecting if it both recalled something that had occurred during the first segment, and evaluated it (i.e., judging whether an action had a good or bad effect, or placing the recalled event within a cause-effect framework). Participants in Non-Feedback Session predominantly recalled actions related to water distribution: the challenge of positioning logs to divide water among biomes ("I wanted to renegotiate our position [meaning, the position of logs that the participant was controlling] and get closer to the water streams as possible" [W1-1]), and describing attempts at negotiating with other groups ("I was literally asking, like, give us some water..." [D1-3]). Reflecting talk more often evaluated actions committed by other participants (e.g., "someone killed my flowers!" [P1-1]) rather than the one's own actions. There were general acknowledgements that the biomes could have "shared water" better, but no details on what that would have entailed (i.e., a lack of cause-effect evaluations).

Prior to introducing the data-driven feedback, the Feedback Session participants' reflecting talk was very similar to that of Non-Feedback Session participants. After seeing the visualization, the bulk of their reflecting talk made use of information drawn from the visualization, as described in the prior section on comprehension. As a consequence, they were able to dive deeper into what made the water distribution unsatisfactory. Virtually all of the talk coded as comprehending in the Feedback Session was also coded as reflecting, showing that decoding the visualization was intimately tied to reflection for the participants.

The Feedback Session participants had agreed by the end of the discussion that not only had the water been distributed unevenly during the first segment (a reflection also made by Non-Feedback Session participants), but they were able to flag which biomes were oversupplied (the Jungle and the Plains) and undersupplied (the Desert), and to set as a goal balancing water supply and the number of plants. As one Wetlands team member remarked: "It doesn't mean that they [Desert] need any water. It means that there weren't any plants that were planted that consumed any water." [W1-2]. The Feedback participants were telling themselves a fundamentally different "story" about their prior participation a "To Each According to Their Needs" narrative, in contrast to the "Share and Share Alike" narrative the Non-Feedback participants generated about their prior experience. Without the data visualization, it is unlikely that the Feedback group would have expanded their reflection beyond the actions of dividing the water supply, to take into account balancing the water supply against the plantings.

\section{Visitors'planning}

Both groups readily engaged in planning talk, coded as talk proposing future action or responding to such proposals. In both cases, large portions of the plans involved how to deal with the coordination aspect of dividing the water flow, but their plans seemed to be strongly influenced by the different reflective narratives generated during their discussions ("Share and Share Alike" versus "To Each According to their Needs"). In the Non-Feedback Session, a participant proposed a "representative democracy" solution, suggesting "we should have a team member to help negotiate with the other team members.... like dedicated will talk about water distribution" [W1-1]. In Feedback Session, they settled on a 

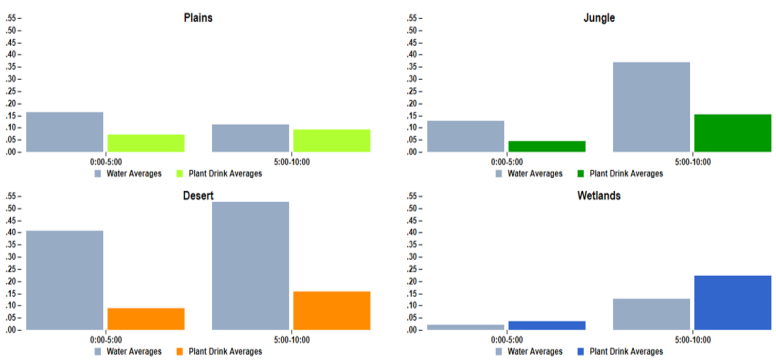

Figure 8: : Visualization of the Non-Feedback group's water supply versus plant needs before and after the discussion, illustrating how their planting and water distribution actions changed after their planning discussion.

phased strategy of first working together to distribute the water across the ecosystems ("maybe we can get water to all ecosystems" [D2-3] via "a unified water irrigation system...." [W2-2]), followed by going back to the teams' biomes and planting ("Maybe we should start around by getting water to places before planting things. And then plant it over where the groundwater is... So, you plant over the most water...very much." [B4-2].) While the plans proposed in both sessions advocated improving the overall ecosystem ("[We need to] compromise...try to get all the biomes to do better" [W2-2]) via equitable water distribution ("I think you need to understand the flow and know how to divide it equally" [J1-2]), only the Feedback Session participants included planting actions in their planning, let alone plan that biomes should essentially "plant within their means." This is compelling evidence that the data-driven feedback strongly informed the plans made by Feedback Session participants.

\section{Visitors' translation of plans into actions}

The information we have regarding visitor actions is derived from recorded logs. When visualized, we can see that despite plans to distribute water evenly among the biomes, neither group was able to do so, per Figures 8 and 9. After the discussion, each session had two biomes with large water supplies (the Desert and the Jungle in Non-Feedback Session, see Figure 8, and the Desert and the Plains in Feedback Session, see Figure 9). To be fair to the participants, distributing water is rather difficult in Connected Worlds, so this may not be evidence of the participants abandoning their plans, so much as just not being able to fully execute them.

What is interesting, though, is that the Feedback Session participants followed through on their intent to "plant within their means." None of the biomes have plantings that outstrip the supply of groundwater (see Figure 9). Moreover, when the plant water needs versus water supply for the Feedback group's post-discussion segment is graphed as in a continuous line graph (Figure 10), it shows that even though they
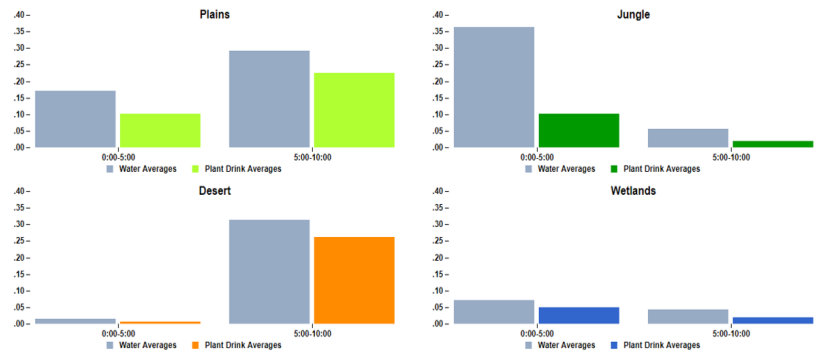

Figure 9: Visualization of the Feedback group's water supply versus plant needs before and after the discussion, illustrating how their planting and water distribution actions changed after their planning discussion.
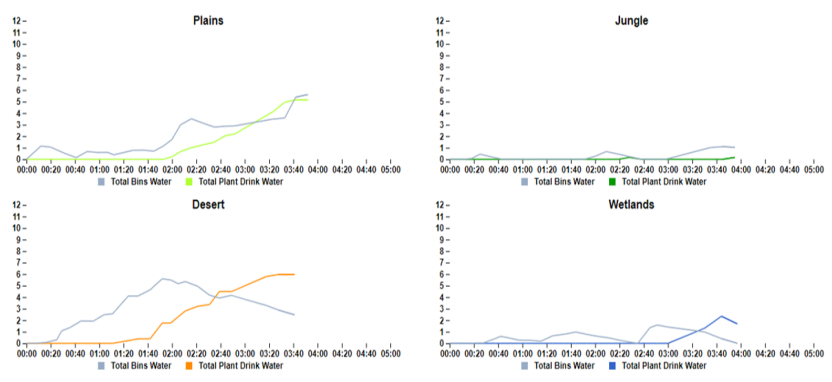

Figure 10: Continuous Plants vs. Water for segment 2 of Feedback Session, showing that participants held to their 2phase plan.

could not divide water evenly, they followed through on their phased plan, waiting to plant until water was present in each biome, and then planting so as to fit within the available water supply (aside from a few overreaches at the end).

\section{Visitors' desired access to exhibit feedback}

The focus group discussions after the two sessions revealed a number of interesting points about the types of access visitors would want to have to data-driven feedback. The majority of participants expressed a desire to have the data available while the visitors actively used the exhibit (as opposed to during facilitated discussion periods), and there was a lot of discussion concerning how that might affect what data is shown, and how. One participant asked to embed $\mathrm{CtCW}$ data visualizations into the Connected Worlds projections themselves, as a sort of data overlay, although that is outside the scope of what we can change. All participants expressed strong interest in being able to view something like $\mathrm{CtCW}$ on their own smart device.

The Feedback Session participants realized that the visualizations might have to be re-conceived for direct use by visitors. For example, they expressed concerns about how to fit the visualizations onto smaller smart-phone screens, 
and while they seemed open to the idea of using museumprovided tablets, several agreed that it might be inconvenient to try to carry large tablets around. This led to a discussion of whether it might actually be better to use simpler forms of data visualization than the examples we presented in the focus group (see Figures 4, 5 and 6) that might more easily suit smart-phone displays. One participant suggested that we should have a way of flagging bar graphs to indicate when action is needed, using the analogy of phone battery indicators, which vibrate and issue alerts when the battery needs recharging. This person suggested that the alert might contain a situationally relevant visualization: "like if you look at the data you would know what you need to do differently." One person wanted us to more clearly call out on the visualization when they made a bad decision, "you can have something visually where it's failing".

Non-Feedback Session participants also proposed using simpler representations, albeit for reasons of comprehension rather than display space. One of the Non-Feedback Session participants found even the simple Plants vs. Water Summary bar graph too complex, saying "having two different variables with this still may be a little too much to focus on you just want like one number, one line, or one bar." Feedback Session participants expressed no difficulties with the representation, and some of them even advocated for adopting the more complex Continuous Plants vs. Water graph (Figure 5) for use in $\mathrm{CtCW}$ (because, as one participant put it, it provided a "more true reading" of their actions).

Both sessions touched on the critical role that data selection can play in influencing visitor actions. One NonFeedback Session participant suggested that we show data that helps direct them towards collective achievement, not competition: "what if these suggested... that while they are in charge of their own [biome], the production of all of them collectively is the goal because they're not fighting over the water, they're trying to figure out the best way to do it [with a] shared resource." A Feedback Session participant similarly suggested that we create a score metric to grade participants on their resource sharing so "we wouldn't have a good score [if] we had the most water, but between mediocre to pretty bad [if] we didn't figure out a way to share our water."

\section{DISCUSSION AND FUTURE WORK}

The focus group discussion raised some interesting questions regarding how visitors should access data from Connected Worlds. Our literature review and prior experience with the Global View suggested that visitors would not stop to consult a visualization while ludically engaged, so incorporating the visualizations into reflective breaks seemed the most productive way to evaluate the prototype for its potential for supporting reflection. The prototype functioned as intended, clearly supporting visitors as they reflected, planned, and translated their plans into action. And yet, the participants expressed strong interest in being able to access Connected Worlds data via their own devices, during their active ludic engagement with the exhibit. Despite the fact that prior work predominantly places educators in the role of mediators of logged data for learners $[10,26,30,31,35,41,45]$, it is true that educators struggled with knowing when to interject moments of reflection into a ludic activity [26, 45]. Perhaps learners themselves would better be able to judge when they need to consult additional information, transitioning themselves from ludic engagement to more of a flow-style of engagement as needed [13]. This could work: in experiential learning scenarios, both children and adults typically engage in reflection after a certain amount of trial-and-error experimentation has failed to produce desired results [8]. With the mobile form factor making this reflective use of data more "ready-at-hand" [46], might visitors be able to break from ludic engagement to seek feedback?

Another observation is that visitors' judgments of the comprehensibility of visualizations are extremely situated. Despite both sessions having identical engagement with Connected Worlds, some Feedback participants requested (screen size allowing) more complex visualizations (like the continuous line graph), while some Non-Feedback Session participants deemed even simple column charts to be too complicated. Having been exposed to the feedback when it was useful seems to have shifted the Feedback group's perception of the feedback's utility and comprehensibility. But they also had a mediator to explain the axes and variables the Non-Feedback group's perceived difficulty indicates that visitors might shy away from using even the simple column graphs if they were to do so on their own. If visitors might find it useful to have even richer data representations in Connect-to-Connected Worlds, how can we structure them, or the manner in which they are delivered, to embrace situated use by visitors without overwhelming them?

It is clear from this study that to design data-driven feedback for use during visitors' engagement, we will need to take a "learning in activity" perspective and consider the ways in which learning is both distributed across and situationally constrained by the activity system it occurs within [20]. In other words, we we will need to create a synergistic design [33] that is sensitive to the factors that support visitors' ongoing narrative engagement with the data, and how they might use the data to drive conversations between one another. Are there ways in which we can "roll out" the visualizations to be part of the emerging story visitors are telling themselves, rather than a distraction from it?

In future work we plan to investigate these issues further. We noticed that Feedback visitors first gravitated towards viewing their own biomes' data, before inspecting and cross comparing other biomes. One way we could sequence the 


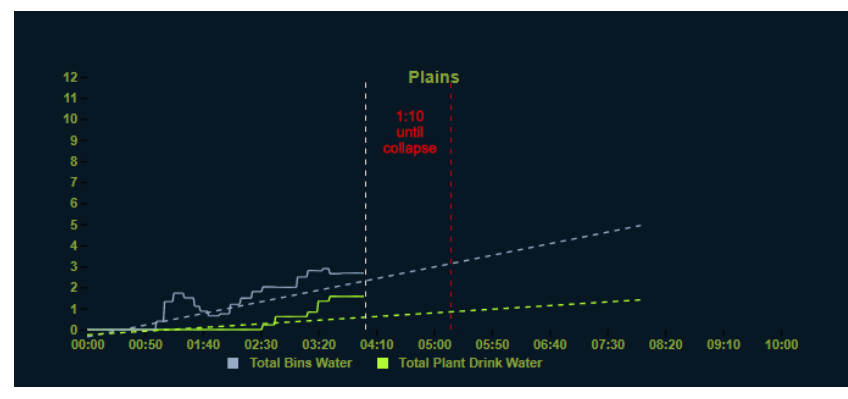

Figure 11: Screen-shot of Continuous Plants vs. Water Prediction: vertical white dashed line indicates the present time, the colored dashed lines show the line-fit trends of water supply and plant needs, and the vertical red dashed line indicates the biome "collapse horizon" (here, in 1m 10s).

delivery of feedback is to follow this natural expansion of visitors' interest, gradually building complexity into the story they can tell with the data rather than providing them with an overwhelming firehose. Another way is to supply different data to different visitors, using the "jigsaw" approach which has been shown to encourage conversation among families [27], so that they can co-construct stories that reconcile the different "perspectives" provided by different data. In addition to studying different means of feedback delivery, we are exploring if amendments to the Continuous Plants vs. Water representation (Figure 5) requested by the Feedback Session participants might make it more accessible during engagement. By including a "collapse horizon" - a timeframe in which actions need to be performed (see Figure 11) - we wish to see if visitors are more readily motivated and able to interpret the visualization (the horizon can be used to issue vibrating alerts as well, if it seems visitors need help with knowing when to seek feedback). In parallel, new funding is permitting us to conduct participatory design sessions with families and with explainers, to explore in a more open-ended fashion how CtCW may need to be designed for family and school group use, respectively. We know that at exhibits children are especially prone to ludic engagement [9], while parents are prone to taking on the "thinking work" for themselves [39]. Whether $\mathrm{CtCW}$ is mediated by parents or explainers, it is likely that the adults will need additional supports - akin to "juicy question" prompts [22] to help translate the data into more equitable discussions.

\section{CONCLUSIONS}

Recorded data of visitor actions could, possibly, serve as a "prosthetic memory" for activities in which visitors were deeply and ludically engaged, helping visitors meld their experiential memories with extra information provided by the logs to support a deeper understanding. In museum contexts, there is an increasing number of digital exhibits which are generating interesting usage data which could promote reflection, but giving visitors feedback in this way is in its infancy. This work shows that data-driven feedback can influence the "stories visitors tell themselves" about an exhibit experience, which is hugely important: the way visitors construct narratives about their museum experiences is known to be a powerful learning mechanism in museums [15, 38], as both conversation and narrative strategies are fundamentally sense-making behaviors [14].

Data-driven feedback helped participants in the Feedback session develop a "To Each According to Their Needs" story about their use of Connected Worlds, a story that made direct use of the variables we provided them, and a story that required the consideration of more information than the simpler "Share and Share Alike" story participants generated in the Non-Feedback session. Expanding beyond our context, the story-framing consequences of data selection and presentation are a big design consideration for formative feedback in open-ended learning settings, and thus could benefit from a more formal consideration of narrative and narrative structures and how they could impact data-driven feedback design. For example, different data subsets or visualizations may or may not support different "plot" structures (mysteries, tales of redemption, etc.). HCI researchers have begun codifying narrative design patterns for presenting data in graphical stories [2], and how interactive technology can advance narratives in the form of interactive theater $[4,24,43]$; such work may have useful suggestions for engineering narratives with data-driven feedback.

A key feature of narratives is that they are inherently sequential - although a story may be told nonlinearly, or begin in media res, the order in which the components of the narrative are revealed is a major part of how it is received by the audience. This concept resonates with the design tension we uncovered concerning when to deliver data-driven feedback to visitors. In prior work, feedback delivered too early could derail visitor engagement [21], the equivalent of reading the last page of a mystery story first. In another exhibit, despite being given "just-in-time" automated alerts that suggested that the moment was right to deliver content, mediators often found the visitors unreceptive [45], demonstrating that a "teachable moment" may not be the same as a "learnable moment" [23]. If just-in-time feedback can be accessed on-demand, when both needed and desired by learners, it might ultimately be better for supporting learning than retrospective reflection - Schön points out that in contrast to "reflection-on-action," "reflection-in-action" yields widerranging learning benefits, which more directly improve people's ability to perform situated tasks [40]. Baumer [5] likens "retrospective reflection" to "slow technology," adopting the analogy from the distinction between gourmet and fast food. We argue that while some forms of just-in-time feedback 
may be as "unhealthy" for learning as a carton of fries, the use of a narrative framing to select which data to present, and when, may be the equivalent of "chewing slowly."

\section{ACKNOWLEDGMENTS}

This material is based upon work supported by the National Science Foundation under Grant Nos. 1623094 and 1822864, and would not have been possible without the aid given by Alyson Casey, Michael Cosaboom and staff.

\section{REFERENCES}

[1] Sue Allen and Joshua P. Gutwill. 2004. Designing With Multiple Interactives: Five Common Pitfalls. Curator 47, 2 (2004), 199-212

[2] Benjamin Bach, Zezhong Wang, Farinella Matteo, Dave Murray-Rust, and Nathalie Henry Riche. 2018. Design Patterns for Data Comics. In ACM Conference on Human Factors in Computing Systems (CHI). https://doi.org/10.1145/3173574.3173612

[3] Pierre Balloffet, Francois H. Courvoisier, and Joelle Lagier. 2014. From Museum to Amusement Park: The Opportunities and Risks of Edutainment. International fournal of Arts Management 16, 2 (2014), 4-16. http://icom.museum/la-vision/defi-

[4] Louise Barkhuus and Chiara Rossitto. 2016. Acting with Technology. Proceedings of the 2016 CHI Conference on Human Factors in Computing Systems - CHI '16 (2016), 864-875. https://doi.org/10.1145/2858036. 2858344

[5] Eric P.S. Baumer. 2015. Reflective Informatics. In Proceedings of the 33rd Annual ACM Conference on Human Factors in Computing Systems - CHI '15. 585-594. https://doi.org/10.1145/2702123.2702234

[6] Robert Bodily and Katrien Verbert. 2017. Trends and issues in studentfacing learning analytics reporting systems research. In Proceedings of the Seventh International Learning Analytics and Knowledge Conference on-LAK'17. ACM Press, New York, 309-318. https://doi.org/10.1145/ 3027385.3027403

[7] Katy Börner, Adam Maltese, Russell Nelson Balliet, and Joe Heimlich. 2016. Investigating aspects of data visualization literacy using 20 information visualizations and 273 science museum visitors. Information Visualization 15, 3 (2016), 198-213. https://doi.org/10.1177/ 1473871615594652

[8] Ann L. Brown, John D. Bransford, R. A. Ferrara, and J. C. Campione. 1983. Learning, remembering, and understanding. In Handbook of child psychology: Cognitive development (iii ed.), P. H. Mussen (Ed.). Wiley, New York, 77-166.

[9] R W Carlisle. 1985. What Do School Children Do at a Science Center? Curator 28, 1 (1985).

[10] Tamara Clegg, Jason Yip, Elizabeth Bonsignore, Jon Froehlich, Leyla Norooz, Seokbin Kang, Virginia Byrne, Monica Katzen, Rafael Valez, Angelisa Plane, Vanessa Oguamanam, and Thomas Outing. 2017. Live Physiological Sensing and Visualization Ecosystems. In Proceedings of the 2017 CHI Conference on Human Factors in Computing Systems CHI '17. 2029-2041. https://doi.org/10.1145/3025453.3025987

[11] Vanessa Colella. 2000. Participatory Simulations: Building Collaborative Understanding Through Immersive Dynamic Modeling. fournal of the Learning Sciences 9, 4 (oct 2000), 471-500. https://doi.org/10. 1207/S15327809JLS0904_4

[12] Kevin J. Crowley, Maureen A. Callanan, Jennifer L. Jipson, Jodi Galco, Karen Topping, and Jeff Shrager. 2001. Shared scientific thinking in everyday parent-child activity. Science Education 85, 6 (2001), 712-732. https://doi.org/10.1002/sce.1035

[13] Mihaly Csikszentmihalyi and Kim Hermanson. 1995. Intrinsic Motivation in Museums: Why Does One Wants to Learn? Public institutions for personal learning, Establishing a research agenda (1995), 67-77. https://doi.org/10.12691/education-2-3-10

[14] E A Davis. 2003. Prompting Middle School Science Students for Productive Reflection: Generic and Directed Prompts. Journal of the Learning Sciences 12, 1 (2003), 91-142.

[15] John H Falk. 2006. An Identity-Centered Approach to Understanding Museum Learning. Curator 49, 2 (2006), 151-166.

[16] John Howard Falk and Lynn Diane Dierking. 2000. Learning from museums: Visitor experiences and the making of meaning. AltaMira Press, Walnut Creek. 272 pages.

[17] Andrew Garbett, David Chatting, Gerard Wilkinson, Clement Lee, and Ahmed Kharrufa. 2018. ThinkActive. In Proceedings of the 2018 CHI Conference on Human Factors in Computing Systems - CHI '18. 1-13. https://doi.org/10.1145/3173574.3173581

[18] William W Gaver, John Bowers, Andrew Boucher, Hans Gellerson, Sarah Pennington, Albrecht Schmidt, Anthony Steed, Nicholas Villars, and Brendan Walker. 2004. The drift table. In Extended abstracts of the 2004 conference on Human factors and computing systems - CHI '04. 885. https://doi.org/10.1145/985921.985947

[19] S. Govaerts, K. Verbert, E. Duval, and A. Pardo. 2012. The student activity meter for awareness and self-reflection. In Extended abstracts on human factors in computing systems (CHI EA '12). 869-884.

[20] James G D B WorldCat D P OCLC Greeno. 2006. Learning in activity. In The Cambridge handbook of the learning sciences, R Keith Sawyer (Ed.). Cambridge University Press, New York.

[21] Joshua P. Gutwill. 2008. Challenging a Common Assumption of Hands-On Exhibits: How Counterintuitive Phenomena Can Undermine Inquiry. The fournal of Museum Education 33, 2 (2008), 187-198. https://doi.org/10.2307/40479643

[22] Joshua P. Gutwill and Sue Allen. 2010. Facilitating Family Group Inquiry at Science Museum Exhibits. Science Education 94, 4 (dec 2010), 710-742. https://doi.org/10.1002/sce.20387

[23] Berit S. Haug. 2014. Inquiry-Based Science: Turning Teachable Moments into Learnable Moments. fournal of Science Teacher Education 25, 1 (feb 2014), 79-96. https://doi.org/10.1007/s10972-013-9375-7

[24] Michaela Honauer, Thomas Keßler, Djamel Merad, Preetha Moorthy, Thien Chinh Nguyen, Jie Qiu, Marie Vogelmann, Patrick Tobias Fischer, Eva Hornecker, Julia Hahn, Bahar Akgün, Claire Dorweiler, Liese Endler, Yvonne Götzl, and Muhammad Raisul Islam. 2017. Dusk. In Proceedings of the 2017 CHI Conference Extended Abstracts on Human Factors in Computing Systems - CHI EA '17. ACM Press, New York, New York, USA, 1037-1045. https://doi.org/10.1145/3027063.3053334

[25] Thomas Humphrey, Joshua P. Gutwill, and Exploratorium APE Team. 2005. Fostering Active Prolonged Engagement: The Art of Creating APE Exhibits. Exploratorium, San Francisco.

[26] Priscilla Jimenez Pazmino, Brenda Lopez Silva, Brian Slattery, and Leilah Lyons. 2013. Teachable mo[bil]ment. In CHI '13 Extended Abstracts on Human Factors in Computing Systems on - CHI EA '13. ACM Press, New York, New York, USA, 643. https://doi.org/10.1145/2468356. 2468470

[27] Eric Klopfer, Susan A. Yoon, and T Um. 2005. Young AdventurersModeling of Complex Dynamic Systems with Elementary \& Middle School Students. Fournal of Computers in Math and Science Teaching 24, 2 (2005), 157-178.

[28] Randi Korn. 1995. An Analysis of Differences Between Visitors at Natural History Museums and Science Centers. Curator: The Museum fournal 38, 3 (1995), 150-160. https://doi.org/10.1111/j.2151-6952.1995. tb01051.x

[29] Vishesh Kumar, Michael Tissenbaum, and Matthew Berland. 2017. What are visitors up to?. In Proceedings of the Seventh International Learning Analytics and Knowledge Conference on - LAK '17. ACM Press, New York, 558-559. https://doi.org/10.1145/3027385.3029456 
[30] Victor R. Lee and Joel Drake. 2013. Quantified recess: design of an activity for elementary students involving analyses of their own movement data. In Proceedings of the 12th International Conference on Interaction Design and Children - IDC '13. ACM Press, New York, 273-276. https://doi.org/10.1145/2485760.2485822

[31] V R Lee, J R Drake, and J L Thayne. 2016. Appropriating Quantified Self Technologies to Support Elementary Statistical Teaching and Learning. IEEE Transactions on Learning Technologies 9, 4 (2016), 354-365. https: //doi.org/10.1109/TLT.2016.2597142

[32] R Lehrer and L Schauble. 2002. Symbolic Communication in Mathematics and Science: Co-Constituting Inscription and Thought. In In E. Amsel and 7. Byrnes (Eds.), Language, literacy, and cognitive development: The development and consequences of symbolic communication. Psychology Press, 185-210. https://doi.org/10.4324/9781410601452-14

[33] Leilah Lyons, E. Anderson, K. Elinich, Michael Tscholl, Christopher Quintana, Jessica Roberts, J. Wang, Susan A. Yoon, and Iris Tabak. 2014. Synergistic scaffolding of technologically-enhanced STEM learning in informal institutions. Proceedings of International Conference of the Learning Sciences, ICLS 3, January (2014).

[34] Roberto Martinez-Maldonado, Yannis Dimitriadis, Alejandra MartinezMonés, Judy Kay, and Kalina Yacef. 2013. Capturing and analyzing verbal and physical collaborative learning interactions at an enriched interactive tabletop. International fournal of Computer-Supported Collaborative Learning 8, 4 (2013). https://doi.org/10.1007/s11412-013-9184-1

[35] Camillia Matuk, Michael Tissenbaum, Matthew Berland, Leilah Lyons, Felipe Cocco, Marcia Linn, Jan L. Plass, Nik Hajny, Al Olsen, Beat Schwendimann, Mina Shirvani Boroujeni, James D. Slotta, Jonathan M. Vitale, Libby Gerard, and Pierre Dillenbourg. 2016. Real-Time Visualization of Student Activities to Support Classroom Orchestration. In ICLS 2016. ACM Press, New York, 1120-1127.

[36] J. Miles, M. B., Huberman, A. M., \& Saldaña. 2014. Qualitative data analysis : a methods sourcebook. SAGE PublicationsSage CA: Los Angeles, CA.

[37] Ann J. Morrison, Peta Mitchell, and Margot Brereton. 2007. The Lens of Ludic Engagement: Evaluating Participation in Interactive Art Installations. In Proceedings of the 15th international conference on Multimedia - MULTIMEDIA '07. ACM Press, New York, New York, USA, 509. https://doi.org/10.1145/1291233.1291358

[38] Lisa C. Roberts. 1997. From Knowledge to Narrative: Educators and the Changing Museum. Smithsonian Institution Press, Washington and London. 205 pages.

[39] Leona Schauble, Mary Gleason, Rich Lehrer, Karol Bartlett, Anthony Petrosino, Annie Allen, Katie Clinton, Evelyn Ho, Melanie Jones,
Young-Sun Lee, Jo-Anne Phillips, John Siegler, and John Street. 2002. Supporting Science Learning in Museums. In Learning Conversations in Museums, Gaea Leinhardt, Kevin Crowley, and Karen Knutson (Eds.). Lawrence Erlbaum, Mahwah, New Jersey, 333-356.

[40] Donald A Schön. 1987. Educating the reflective practitioner. Jossey-Bass San Francisco.

[41] Beat A. Schwendimann, Maria Jesus Rodriguez-Triana, Andrii Vozniuk, Luis P. Prieto, Mina Shirvani Boroujeni, Adrian Holzer, Denis Gillet, and Pierre Dillenbourg. 2017. Perceiving Learning at a Glance: A Systematic Literature Review of Learning Dashboard Research. IEEE Transactions on Learning Technologies 10, 1 (jan 2017), 30-41. https: //doi.org/10.1109/TLT.2016.2599522

[42] Phoebe Sengers, Kirsten Boehner, Michael Mateas, and Geri Gay. 2008. The disenchantment of affect. Personal and Ubiquitous Computing 12, 5 (jun 2008), 347-358. https://doi.org/10.1007/s00779-007-0161-4

[43] Michael Warren Skirpan, Jacqueline Cameron, and Tom Yeh. 2018. More Than a Show. In Proceedings of the 2018 CHI Conference on Human Factors in Computing Systems - CHI '18. ACM Press, New York, New York, USA, 1-13. https://doi.org/10.1145/3173574.3174038

[44] Morten A. Skydsgaard, Hanne Møller Andersen, and Heather King. 2016. Designing museum exhibits that facilitate visitor reflection and discussion. Museum Management and Curatorship 31, 1 (2016). https://doi.org/10.1080/09647775.2015.1117237

[45] Brian Slattery, Leilah Lyons, Priscilla Jimenez Pazmino, Brenda Lopez Silva, and Thomas Moher. 2014. How interpreters make use of technological supports in an interactive zoo exhibit.. In Proceedings of the 11th International Conference of the Learning Sciences (ICLS 2014), Vol. 1. Boulder, CO, 198-205.

[46] Elliot Soloway, Cathleen Norris, Phyllis C. Blumenfeld, Barry J. Fishman, Joseph S. Krajcik, and R Marx. 2001. Handheld Devices are Ready-at-Hand. Commun. ACM 44, 6 (2001), 15-20.

[47] R.E. Stake. 2013. Multiple Case Study Analysis. Guilford Publications.

[48] Michael Tscholl and Robb Lindgren. 2016. Designing for Learning Conversations: How Parents Support Children's Science Learning Within an Immersive Simulation. Science Education 100, 5 (2016), 877-902. https://doi.org/10.1002/sce.21228

[49] Katrien Verbert, Sten Govaerts, Erik Duval, Jose Luis Santos, Frans Van Assche, Gonzalo Parra, and Joris Klerkx. 2013. Learning dashboards: an overview and future research opportunities. Personal and Ubiquitous Computing 18, 6 (nov 2013), 1499-1514. https://doi.org/10. 1007/s00779-013-0751-2

[50] Robert K Yin. 2017. Case study research and applications: Design and methods. Sage publications. 